\title{
Paniculitis pancreática como primer signo de adenocarcinoma de páncreas con metástasis hepáticas
}

\author{
Munia García-Gómez¹, Alberto Montero-Rodríguez', Pedro Ángel Cuadros-Tito', Arantza Onaindia-Pérez² \\ 'Servicio de Medicina Interna, Hospital Alto Deba, Organización Sanitaria Integrada Debagoiena, Arrasate, Guipúzcoa, España \\ ${ }_{2}^{2}$ Servicio de Anatomía Patológica, Hospital Universitario de Araba, Vitoria Gasteiz, España
}

Recibido: 13/05/2021

Aceptado: 14/09/2021

En línea: $31 / 12 / 2021$

Citar como: García-Gómez M, Montero-Rodríguez A, Cuadros-Tito PÁ, Onaindia-Pérez A. Paniculitis pancreática como primer signo de adenocarcinoma de páncreas con metástasis hepáticas. Rev Esp Casos Clin Med Intern (RECCMI). 2021 (dic); 6(3): 6-8. doi: 10.32818/reccmi.a6n3a3.

Cite this as: García-Gómez M, Montero-Rodríguez A, Cuadros-Tito PÁ, Onaindia-Pérez A. Pancreatic panniculitis as the first sign of pancreatic adenocarcinoma with liver metastases. Rev Esp Casos Clin Med Intern (RECCMI). 2021 (Dec); 6(3): 6-8. doi: 10.32818/reccmi.a6n3a3.

Autor para correspondencia: Munia García-Gómez.munia.garciagomez@osakidetza.eus

\section{Palabras clave}

$\triangle$ Paniculitis

$\triangleright$ Páncreas

$\triangleright$ Carcinoma

\begin{abstract}
Resumen
La paniculitis pancreática es una entidad septal-lobulillar poco común. Se caracteriza por la aparición de lesiones eritemato-violáceas o nódulos subcutáneos ulcerados a veces dolorosos localizados más frecuentemente en extremidades inferiores. Está asociada a trastornos pancreáticos y en ocasiones se manifiesta como primer signo de patología pancreática concomitante: pancreatitis aguda o crónica, carcinoma pancreático, pseudoquistes pancreáticos, pancreatitis traumática... El diagnóstico se confirma mediante análisis anatomopatológico.

Se presenta el caso de un varón de 78 años con nódulos subcutáneos en extremidades inferiores sin otros síntomas acompañantes con diagnóstico de paniculitis pancreática y hallazgos de adenocarcinoma de páncreas con metástasis hepáticas en pruebas de imagen complementarias.
\end{abstract}

\begin{tabular}{l} 
Keywords \\
$\triangleright$ Panniculitis \\
$\triangleright$ Pancreas \\
$\triangleright$ Carcinoma \\
\hline
\end{tabular}

\section{Puntos destacados}

- Las lesiones cutáneas, en ocasiones, son manifestación de una enfermedad sistémica.

- En el caso de las paniculitis es imprescindible el diagnóstico etiológico y, para ello, una herramienta clave es la biopsia cutánea.

\section{Introducción}

La paniculitis pancreática (también denominada necrosis grasa pancreática) es una paniculitis mixta septal-lobulillar que se manifiesta aproximadamente en el 2-3\% de los enfermos con trastornos pancreáticos ${ }^{1}$. Se caracteriza por la aparición de lesiones eritemato-violáceas o nódulos subcutáneos ulcerados, a veces dolorosos, localizados más frecuentemente en extremidades inferiores, aunque pueden localizarse en cualquier parte del cuerpo.
En esta enfermedad, a diferencia de otras paniculitis, los nódulos pueden sufrir una necrosis licuefativa que conlleva a una ulceración de la lesión con drenaje de material oleoso. Esta erupción sucede por la liberación masiva de enzimas lipolíticas de origen pancreático al torrente sanguíneo’.

La paniculitis pancreática está asociada a trastornos pancreáticos y, en ocasiones, se manifiesta como primer signo de patología pancreática concomitante: pancreatitis aguda o crónica, carcinoma pancreático, pseudoquistes pancreáticos, pancreatitis traumática... ${ }^{2,3}$ Incluso en determinados casos la manifestación de estas lesiones puede indicar la presencia de enfermedad metastásica. En consecuencia, ante su presencia hay que descartar patología pancreática.

El diagnóstico se confirma mediante análisis anatomopatológico donde es característico la necrosis de adipocitos y la presencia de «células fantasma» (adipocitos sin núcleo) con depósitos de calcio². 
Munia García-Gómez, Alberto Montero-Rodríguez, Pedro Ángel Cuadros-Tito, Arantza Onaindia-Pérez Paniculitis pancreática como primer signo de adenocarcinoma de páncreas con metástasis hepáticas

\section{Caso clínico}

\section{Antecedentes y enfermedad actual}

Varón de 78 años consumidor moderado de alcohol, hipertenso y dislipémico con infarto agudo de miocardio anterolateral en 2018 con revascularización percutánea e hiperplasia ductal atípica en mama izquierda. Está intervenido de mama izquierda, colecistectomizado y portador de prótesis femoral derecha. En tratamiento habitual con ácido acetilsalicílico, carvedilol, olmesartan/hidroclorotiazida, atorvastatina, tamsulosina y alopurinol.

El paciente ingresa por nódulos subcutáneos bilaterales no dolorosos en ambas extremidades inferiores, teniendo alguno de ellos un exudado purulento sin otra sintomatología acompañante (Figuras 1 y 2). Se catalogó de celulitis y recibió antibioterapia endovenosa con ceftriaxona y, posteriormente, amoxicilina-clavulánico por vía oral con remisión de las lesiones, que reaparecieron tras finalizar el tratamiento. Por ello, reingreso para estudio de los nódulos subcutáneos bilaterales en ambas extremidades inferiores de 3 meses de evolución sin otra sintomatología asociada.

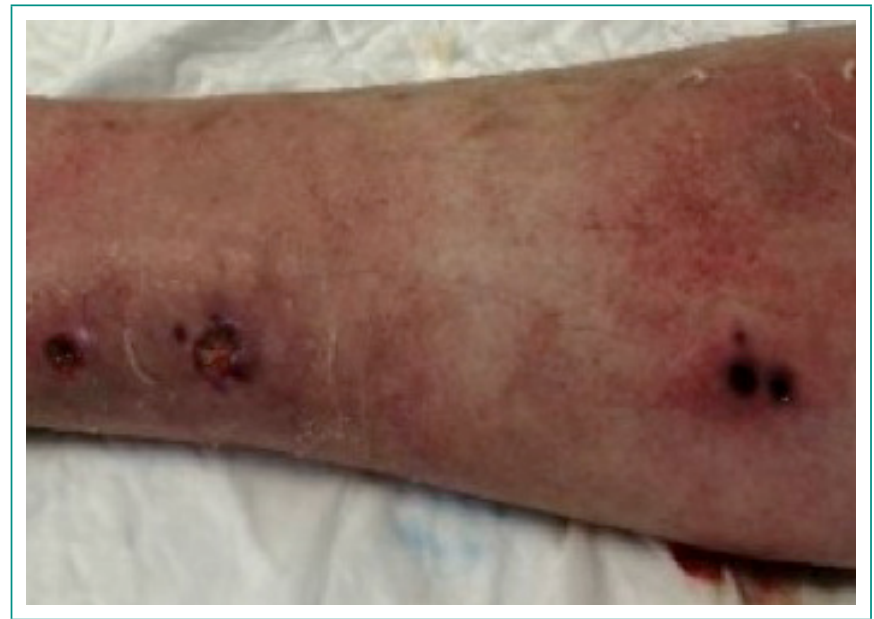

Figura 1. Imagen clínica de la cara lateral interna de extremidad inferior derecha con 3 lesiones ulceradas una de ellas con material exudativo.

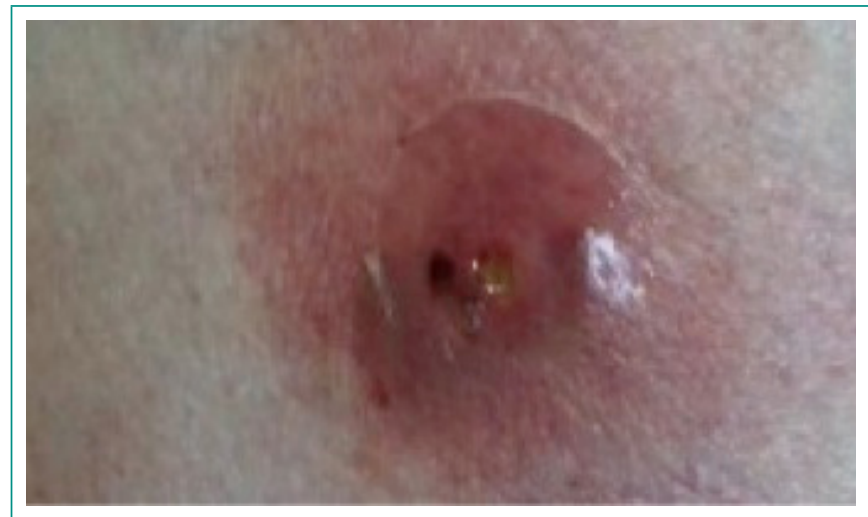

Figura 2. Detalle de imagen de nódulo eritematoso con exudado oleoso en misma extremidad.

\section{Pruebas complementarias}

Analíticamente destaca la elevación de lipasa a 797 U/L (valor normal 0-78) con amilasa normal, marcadores tumorales negativos, GGT de $92 \mathrm{U} / \mathrm{L}$ (valor normal 8-64), Dímero D de $10.798 \mathrm{ng} / \mathrm{mL}$ (valor normal 0-500), VSG de $62 \mathrm{~mm}$ (valor normal 0-15). y fosfatasa alcalina de $184 \mathrm{U} / \mathrm{L}$ (valor normal 40-150).
Se realiza biopsia cutánea de lesión localizada en extremidad inferior derecha en la que se observa (Figura 3) paniculitis de patrón septo-lobulillar, con presencia de un infiltrado mixto, con linfocitos y numerosos eosinófilos. Se observan áreas de necrosis adiposa con formación de membrana hialina y abundante polvillo nuclear. Existen infiltrados perivasculares superficiales en dermis papilar de predominio linfocitario, inespecíficos.

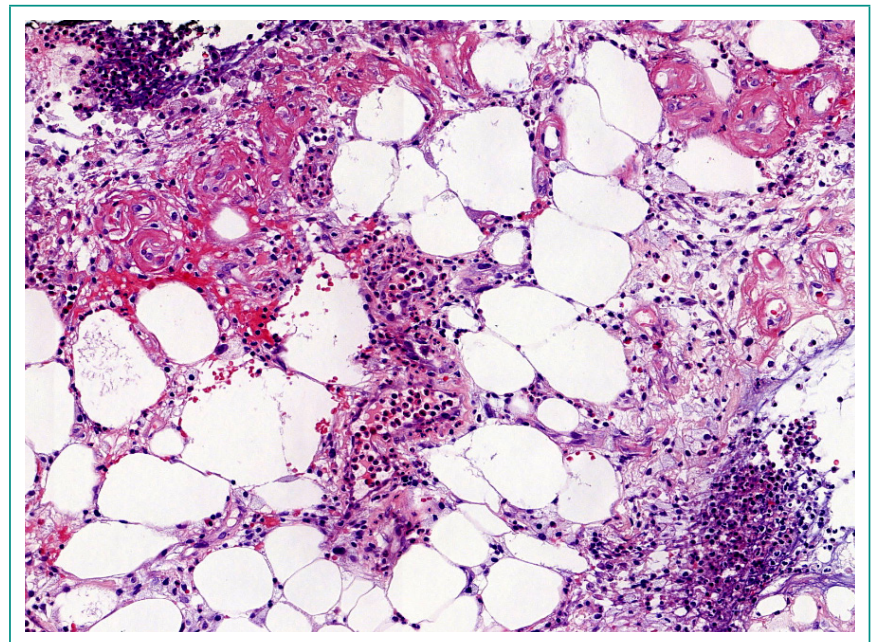

Figura 3. Estudio histopatológico de la lesión localizada en extremidad inferior derecha con necrosis adiposa.

Ante el hallazgo histológico de paniculitis septal-lobulillar compatible con paniculitis pancreática se realizan pruebas complementarias para buscar afectación pancreática.

El TAC toraco-abdominal (Figura 4) mostró una amputación del conducto de Wirsung con sensación de masa en cabeza de páncreas y proceso uncinado pancreático asociados a adenopatías locales que sugirieron una neoplasia pancreática. También se identificaron lesiones focales hepáticas sugestivas de metástasis.

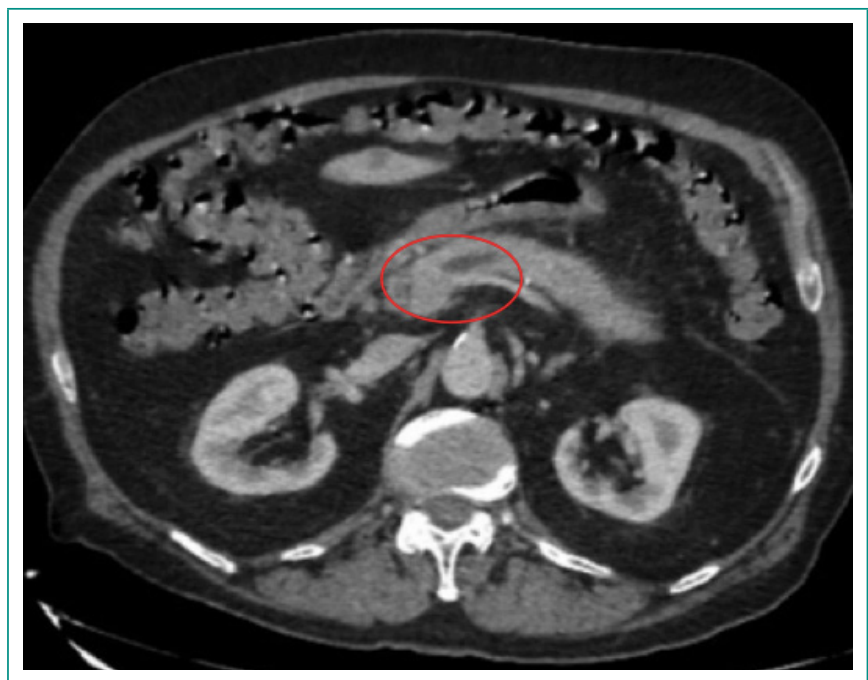

Figura 4. TAC toraco-abdominal. Sensación de masa en cabeza (círculo rojo) y proceso uncinado pancreáticos asociados a adenopatías locales.

La RMN abdominal (Figura 5) ratificó estos hallazgos y mostró rarefacción de la grasa en torno a la cabeza del páncreas, con alguna adenopatía local y dilatación del Wirsung hasta la zona cefálica. Y una sutil zona hipocaptante de unos $3 \mathrm{~cm}$ a nivel de cabeza pancreática. 

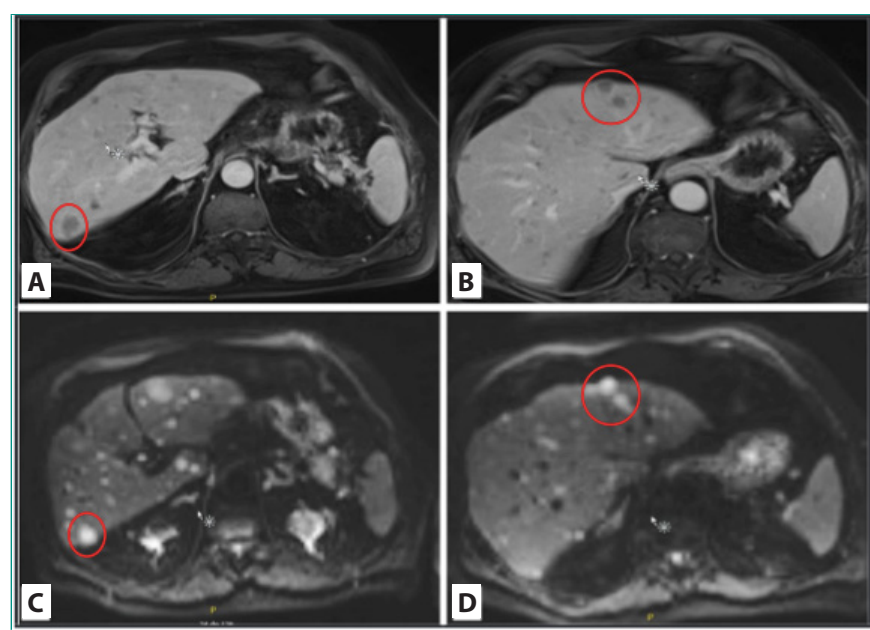

Figura 5. RMN abdominal. Se muestran 2 secuencias diferenciadas (A, B) y (C, D) tanto en T1 como en T1 con alta difusión donde se objetivan marcados en círculos rojos lesiones ocupantes de espacio hepáticas sospechosas de metástasis.

\section{Evolución}

Tras realización de las pruebas comentadas y establecer el diagnóstico de paniculitis pancreática se completó estudio con ecoendoscopia y PAAF con resultado de adenocarcinoma pancreático y metástasis hepáticas. Finalmente se derivó el paciente a Oncología donde comenzó quimioterapia con gemcitabina endovenosa en monoterapia, a pesar de lo cual se produjo el fallecimiento unos meses después.

\section{Diagnóstico}

Paniculitis pancreática como debut de adenocarcinoma de páncreas con metástasis hepáticas.

\section{Discusión}

La paniculitis pancreática clínicamente es casi indistinguible de otras paniculitis por lo que el diagnóstico diferencial debe incluir un amplio abanico de enfermedades tales como el eritema nodoso, el eritema indurado o un proceso infeccioso concomitante ${ }^{2,3}$. Puede desencadenarse con menos frecuencia debido al uso de algunos fármacos (corticoides, sulfasalazina, tiazidas, anticonceptivos orales... $)^{3}$. Es una entidad que predomina en el sexo masculino, y tiene mayor prevalencia en pacientes con consumo enólico.

La base de la confirmación diagnóstica es la biopsia cutánea por sus hallazgos histopatológicos característicos: paniculitis preferentemente lobulillar aunque al inicio de los nódulos puede ser septal, «células fantasma» (células anucleadas con una membrana gruesa) que representan adipocitos parcialmente digeridos por enzimas pancreáticas junto a microcalcificaciones apreciadas como material basófilo que expresan la saponificación de los lípidos por las sales de calcio $^{2}$.

A pesar de ser inespecífica, la paniculitis pancreática se diferencia de las demás paniculitis por la secreción oleosa de las lesiones ulceradas localizadas con mayor frecuencia en extremidades inferiores, así como la elevación de lipasa y en ocasiones de amilasa. Hay casos en que esta enfermedad se acompaña de artritis, fiebre, ascitis, dolor abdominal y derrames pleurales².
De forma general, esta paniculitis está asociada a patología pancreática tanto benigna como maligna incluso como primer signo de trastorno pancreático.

Ante una paniculitis es imprescindible realizar un diagnóstico etiológico mediante biopsia y un estudio para descartar patología sistémica asociada o fenómeno paraneopásico incluso en pacientes asintomáticos mediante realización de analíticas sanguíneas y pruebas de imagen complementarias. En muchas ocasiones las lesiones cutáneas preceden al diagnóstico de la afección pancreática como en el caso presentado.

En el caso de aparecer asociada a un proceso neoplásico lo hace con mayor frecuencia con el carcinoma de células acinares, a diferencia de nuestro caso que se presentó como adenocarcinoma pancreático ${ }^{4}$.

La fisiopatología de la enfermedad es controvertida, pero se cree que es debido a la liberación masiva de enzimas pancreáticas como lipasa, amilasa, tripsina... al torrente sanguíneo'. Consecuentemente, se genera una alteración de la permeabilidad de los vasos, hidrólisis de grasas neutras y finalmente necrosis e inflamación de las grasas. Los niveles de lipasa pancreática, por ello, pueden encontrarse aumentados tanto en sangre como en las propias lesiones cutáneas. Al parecer, las lesiones de la piel y el páncreas comparten la fosfolipasa A2 como mediador ${ }^{5}$

Para concluir, en distintas revisiones consultadas se describen casos clínicos similares de paniculitis pancreática como hallazgo inicial de carcinoma de páncreas diagnosticado mediante pruebas de imagen complementarias ${ }^{1,46}$. En dos de las revisiones, como en el caso presentado, el carcinoma se asoció con metástasis hepáticas ${ }^{7.8}$.

\section{Bibliografía}

1. Segurado Rodríguez A, Guerra Tapia A, Jaén Olasolo P, Cuevas Santos J. Paniculitis pancreática: estudio de 12 casos y valoración comparativa de sus caracteres epidemiológicos, clínicos, histopatológicos y terapéuticos. Actas Dermosifiliogr. 1999; 90: 227-34. Accesible en: https://www.actasdermo. org/es-pdf-13003487 (último acceso: mayo 2021).

2. Bolognia JL, Schaffer JV, Cerroni L. Dermatología. 4a edición. Elsevier. 2018; 100 (2): 1733-1757.

3. Requena L, Sánchez Yus E. Panniculitis. Part II. Mostly lobular panniculitis. J Am Acad Dermatol. 2001; 45(3): 325-61; quiz 362-4. doi: 10.1067/ mjd.2001.114735.

4. de la Torre Gomar FJ, Heras González S, Pérez Rodríguez Á, S Enz Aguirre A, Martínez de Lagrán Álvarez de Arcaya Z. Paniculitis pancreática como forma de presentación de neoplasia localmente avanzada. Gastroenterol Hepatol. 2020; 43(6): 325-326. doi: 10.1016/j.gastrohep.2019.11.011.

5. Ballester R, De Unamuno B, Hernández P, Torrijos A, Alegre de Miguel V. Paniculitis pancreática. Revisión de 7 casos. Piel formación continuada en Dermatología (Barcelona). Elsevier. 2012; 27 (7): 367-371.

6. Zhang G, Cao Z, Yang G, Wu W, Zhang T, Zhao Y. Pancreatic panniculitis associated with pancreatic carcinoma: A case report. Medicine (Baltimore). 2016 Aug; 95(31): e4374. doi: 10.1097/MD.0000000000004374.

7. de Frutos Rosa D, Espinosa Taranilla L, González de Canales de Simón P, Vélez Velázquez MD, Guirado Koch C. Pancreatic panniculitis as a presentation symptom of acinar cell carcinoma. Rev Esp Enferm Dig. 2018; 110(5): 329331. doi: 10.17235/reed.2018.5203/2017.

8. Guanziroli E, Colombo A, Coggi A, Gianotti R, Marzano AV. Pancreatic panniculitis: the "bright" side of the moon in solid cancer patients. BMC Gastroenterol. 2018; 18(1): 1. doi: 10.1186/s12876-017-0727-1. 